\title{
Reye's syndrome in the British Isles: first annual report of the joint British Paediatric Association and Communicable Disease Surveillance Centre surveillance scheme
}

\author{
S HALL, M BELLMAN
}

Reye's syndrome is a severe acute paediatric disorder characterised by encephalopathy with pronounced cerebral oedema and by diffuse fatty infiltration of the viscera, particularly the liver. ${ }^{1}$ It may occur at any age in childhood.

Typically a previously normal child has a viral type prodromal illness followed in a few days by vomiting, altered consciousness, and often convulsions. The liver may be enlarged and there may be evidence of hepatic dysfunction, with raised activities of transaminase, raised blood ammonia concentrations, and sometimes hypoglycaemia and a prolonged prothrombin time. At necropsy the liver is enlarged, pale, and fatty, and histological examination shows diffuse, panlobular microvesicular fatty infiltration. Fatty changes may also be seen in skeletal muscle, heart, and kidneys. Characteristic ultrastructural cellular changes have been described. ${ }^{2}$

The aetiology of Reye's syndrome is unknown, but it is thought to represent an abnormal reaction to a viral infection in a genetically susceptible host, possibly modified by exogenous toxins. ${ }^{3}$ Influenza $\mathrm{B}$ and $\mathrm{A}$ and varicella zoster have been the most consistently associated viruses, although Reye's syndrome has been reported after many other viral infections. ${ }^{3}$

Much of the epidemiological information about Reye's syndrome comes from the United States, where the Centers for Disease Control have maintained national surveillance for over 10 years. In Britain some data on Reye's syndrome in children under 3 years old were obtained from the National Childhood Encephalopathy Study. ${ }^{4}$ In view of the lack of epidemiological knowledge about Reye's syndrome in children of all ages in the British Isles, a joint voluntary Reye's syndrome reporting scheme was started by the British Paediatric Association and the Communicable Disease Surveillance Centre in August 1981 with the aim of (a) documenting the occurrence and describing the characteristics of Reye's syndrome in the British Isles and monitoring long term trends; and $(b)$ providing a central case register and serum and tissue bank for clinical or laboratory research. This paper reports the results obtained in the first year of the surveillance scheme, August 1981 to July 1982.

\footnotetext{
Public Health Laboratory Service Communicable Disease Surveillance Centre, London NW9 5EQ

$S$ HALL, MB, MFCM, senior registrar in epidemiology
}

Academic Department of Child Health, Queen Elizabeth Hospital for Children, London E2

M BELLMAN, MB, MRCP, lecturer in child health

Correspondence to: Dr Hall.

\begin{abstract}
Methods
The case definition used was encephalopathy of unknown cause, plus either histological appearances in the liver showing characteristic fatty changes or serum transaminase activities raised above $100 \mathrm{IU} / \mathrm{l}$. A clinically enlarged liver, raised blood ammonia concentrations, hypoglycaemia, or an increased prothrombin time were accepted as supportive evidence but were not essential.

For the analysis, a case was considered "definite" if there was histological confirmation. It was "possible" if there was encephalopathy with raised transaminase activities with either no histological examination, or some unusual clinical, biochemical, or histological feature and no more reasonable explanation for the encephalopathy. Information supplied by paediatricians on a standard questionnaire was collated by the Communicable Disease Surveillance Centre. Pathological specimens were stored at the virus reference laboratory of the Central Public Health Laboratory. Information on certified deaths from Reye's syndrome in England and Wales was obtained from the Office of Population, Censuses, and Surveys, who provided copies of death certificates on which Reye's syndrome was mentioned as a cause of death, from January 1982 onwards. Information on possible deaths from Reye's syndrome for the years 1979-81 was also obtained from the Office of Population, Censuses, and Surveys, using ICD 331.8, the code for deaths from "other cerebral degeneration," which includes Reye's syndrome.
\end{abstract}

\section{Results}

Thirty patients with encephalopathy and serum transaminase activities raised above $100 \mathrm{IU} / \mathrm{l}$ were reported from 17 hospitals (see table I). The numbers of deaths recorded (ICD 331.8) in children aged 15 and under for 1979, 1980, and 1981 were 13, eight, and 14 respectively. For the period January to July 1982 the Office of Population, Censuses, and Surveys received 14 death certificates where the cause of death was ascribed to Reye's syndrome. Six of these patients had not been reported to the surveillance scheme.

The mean age of the patients with definite Reye's syndrome (6 years, 4 months) was nearly three times that of patients with possible Reye's syndrome and more than nine times greater than that of children classified as not Reye's syndrome. Of the 11 patients with definite Reye's syndrome, nine had a prodromal illness, three had severe vomiting, seven had hypoglycaemia, and all in whom the investigation was undertaken had hyperammonaemia. Six of the 16 patients in the "possible" group had no prodrome, only two had severe vomiting, and two out of nine investigated were normoammonaemic. 
Four children in the possible group and all three diagnosed as not having Reye's syndrome had some clinical or biochemical features unusual for Reye's syndrome. One had a blood ammonia concentration less than $100 \mu \mathrm{g} / \mathrm{l}$; two were previously mentally retarded epileptics who had been treated with carbamazepine and phenytoin for three years and one year respectively. Two patients in the possible group had fever and disseminated intravascular coagulation; one, aged 8 months, had a normal blood ammonia concentration and developed severe diarrhoea and profound shock. His diagnosis was later revised to haemorrhagic shock and encephalopathy syndrome. ${ }^{5}$ The other had a history of epilepsy and severe neurodevelopmental abnormality and had been taking carbamazepine, sodium valproate, and primidone for over a year.

Two patients were subsequently diagnosed as having inborn errors of metabolism. One had glutaric aciduria type 2 , and the other, who had hyperbilirubinaemia and persistent hyperammonaemia during the Reye like illness, had $\alpha$ antitrypsin deficiency. The encephalopathy was later ascribed to a cerebral haemorrhage.

\section{PATHOLOGICAL FINDINGS}

In nine out of 10 necropsy reports the macroscopic appearance of the liver was large, pale, and fatty. In the patient with haemorrhagic shock and encephalopathy syndrome it was "shrunken and yellow."

Of 17 patients whose livers were examined histologically either before or after death, 11 showed the characteristic changes of Reye's syndrome; these were all classified as definite cases. Four of the 17 patients were assigned to the possible group: one was reported to have "inconclusive glycogen vacuolation"; the one with only minimally raised ammonia

TABLE I-Age and clinical and biochemical features of reported cases

\begin{tabular}{|c|c|c|c|}
\hline Feature & $\begin{array}{l}\text { Definite } \\
\text { cases } \\
(n=11)\end{array}$ & $\begin{array}{l}\text { Possible } \\
\text { cases } \\
(n=16)\end{array}$ & $\begin{array}{c}\text { Not Reye's } \\
\text { syndrome } \\
(\mathrm{n}=3)\end{array}$ \\
\hline $\begin{array}{l}\text { Mean age in months (range) } \\
\text { Prodrome present } \\
\text { Antecedent vomitins: }\end{array}$ & $\underset{9}{76} \cdot 5(3-308)$ & $\begin{array}{l}26(3-96) \\
10\end{array}$ & $\begin{array}{l}8(2-14) \\
3\end{array}$ \\
\hline Minimal & 5 & 5 & 1 \\
\hline Moderate-severe & 3 & 2 & 0 \\
\hline Coma (pain responsive and non-responsive) & 6 & 10 & 3 \\
\hline Hepatomegaly & 3 & 9 & 3 \\
\hline $\begin{array}{l}\text { Hyperammonaemia } \\
\text { Hypoglycaemia }\end{array}$ & $9(9)$ & $\begin{array}{l}7(9) \\
8(15)\end{array}$ & 1 \\
\hline Prolonged prothrombin time $(>2 \times$ control $) \dagger$ & $7(8)$ & $12(13)$ & 3 \\
\hline Normal cerebrospinal fluid & $10^{*}$ & $15+$ & 3 \\
\hline $\begin{array}{l}\text { Outcome: } \\
\text { Died }\end{array}$ & \multicolumn{2}{|c|}{ Outcome: } & 1 \\
\hline Survived with neurological damage & 0 & 6 & 1 \\
\hline Survived normal & 3 & 2 & 1 \\
\hline
\end{tabular}

$* 1$ case had $13 \times 10^{6}$ white blood cells/1.

$\dagger$ Numbers in parentheses are numbers of children tested if not all investigated.

$\ddagger 1$ case had protein $5 \cdot 7 \mathrm{~g} / 1$. concentration had mixed large and small intracellular fat droplets; in one the microvesicular fat was accompanied by central and midzonal necrosis in every lobule; the fourth, who did not have atypical clinical or biochemical features, had "large" fat droplets.

A viral infection was identified in nine of the 25 patients investigated virologically. Only one patient had had influenza $B$, and one had varicella. Four echovirus infections (three different serotypes) were identified. One patient had Mycoplasma pneumoniae.

\section{EPIDEMIOLOGY (27 DEFINITE AND POSSIBLE CASES)}

The epidemiological findings are shown in table II, which also summarises data from the United States for ease of comparison. The incidence, at $0 \cdot 21$ per 100000 population under 15 years in the British Isles, was lower than that in the United States; the overall average age, 3 years 10 months, was younger, although the mean age of our histologically confirmed cases, 6 years 4 months, was more comparable; there was no obvious rural predilection; a third of the cases were reported from Ireland; there was no clear winter peak, although there was a possible small cluster in February and March 1982; a higher proportion of British cases had no prodrome; mortality, at $59 \%$, was more than double the recent American figures.

\section{Discussion}

Two principal findings have emerged from the first year of the surveillance scheme. Firstly, the low incidence in Britain compared with North America was not unexpected for the first year of a new reporting scheme and is as likely to be due to underreporting, or underdiagnosis, or both, as to a real difference. Although in previous years the number of deaths certified as due to Reye's syndrome was similar to the number of those reported to the surveillance scheme in its first year, direct comparison of reports of Reye's syndrome and deaths certified as being due to Reye's syndrome in the first six months of 1982 suggested a reporting rate of only about a half. A high mortality is also to be expected in the early stages of a new reporting scheme because of preferential diagnosis and reporting of more severe cases. The low mean age was comparable to that originally described by Reye $^{1}$ and by others ${ }^{6}{ }^{7}$ and may partly account for the differences in mortality and the prevalence of antecedent illness. Although there was an influenza $B$ epidemic in the winter of 1982 in Britain, no clear association with this organism was apparent.

Secondly, there were problems of case definition: atypical patients who presented with a Reye like illness and were included because they met the case definition show that the criteria have a relatively low specificity. This difficulty does not in-

TABLE II-Epidemiological features of Reye's syndrome: comparison of United States findings and first year of British surveillance scheme (27 definite and possible cases)

\begin{tabular}{|c|c|c|}
\hline Feature & USA $(<18 \text { years, } 1973-81)^{3}$ & British Isles ( -15 years, 1 Aug $1981-31$ July 1982) \\
\hline $\begin{array}{l}\text { Incidence/10\%/year } \\
\text { Mean age (years): } \\
\text { All cases } \\
\text { Respiratory prodrome } \\
\text { Varicella, gastrointestinal prodrome } \\
\text { No prodrome } \\
\text { Sex } \\
\text { Temporal and seasonal distribution } \\
\text { Geographical distribution } \\
\text { Type of prodrome ( } \% \text { of cases): } \\
\text { Flu-like } \\
\text { Gastroenteritis } \\
\text { Varicella } \\
\text { None or other } \\
\text { Mortality: } \\
\% \text { of cases }\end{array}$ & $\begin{array}{l}0 \cdot 37-0 \cdot 88 ; 2-4 \text { during influenza epidemics } \\
8-9 \\
8-11 \\
6 \\
\text { Slight excess of girls } \\
\text { "Epidemic" years coinciding with influenza B: winter peaks } \\
\text { especially February } \\
\text { Higher incidence in north central states and in rural, } \\
\text { compared with urban, areas } \\
\text { 1974 (flu B yr) } 1977 \text { (flu A yr) } \\
89 \\
4 \\
7\end{array}$ & $\begin{array}{l}0.21 \\
3 \text { yr } 10 \text { mnth (median } 14 \text { mnth, range } 3 \text { mnth-14 yr) } \\
4 \text { yr } 10 \text { mnth } \\
3 \text { yr } 5 \text { mnth } \\
16 \mathrm{mnth} \\
12 \mathrm{M} 15 \mathrm{~F} \\
\text { No marked seasonality but possible small cluster February and } \\
\text { March } 1982 \\
\text { No rural predilection: one third of cases reported from Ireland, } \\
\text { no cases from north east England or south Wales } \\
1981-2 \text { (flu B yr t some flu A) } \\
37 \text { (10 cases) } \\
29 \text { ( } 8 \text { cases) } \\
33 \text { (1 case) } \\
27 \text { (8 cases) } \\
59 \text { (16 deaths) }\end{array}$ \\
\hline
\end{tabular}


validate comparisons with the United States data because the Centers for Disease Control's Annual Surveillance Reports do not publish corrected figures for those cases in which a change of diagnosis is made.

The case criteria used by the surveillance scheme and by the Centers for Disease Control ${ }^{3}$ allow the diagnosis of Reye's syndrome to be made on clinical and biochemical grounds alone. This has been validated by comparison with histology (light microscopy only) in only one large series. ${ }^{8}$ The case definition is practical and sensitive, given that clinicians are naturally reluctant to undertake liver biopsy in very sick children with prolonged prothrombin times, but it lacks specificity because of the wide differential diagnosis. ${ }^{9}$ The marked mean age difference between histologically confirmed cases and the others in our series emphasises the need for such confirmation in infants and younger children who, as a group, may be more likely to have metabolic disorders than Reye's syndrome. ${ }^{9}$ If histological confirmation of Reye's syndrome cannot be obtained, material should be examined after death. Parents may agree to an immediate liver biopsy after death even if consent for necropsy is refused. The Centers for Disease Control case definition excludes patients with over $8 \times 10^{6}$ white blood cells/ 1 in the cerebrospinal fluid, although histologically proved Reye's syndrome with cerebrospinal fluid pleocytosis, reported in one of our cases (table I), has been described, though it is rare. ${ }^{8}$ Thus case definitions of Reye's syndrome should be used as diagnostic guides, rather than for a rigid differentiation of cases and non-cases which requires histological examination.

\section{Further studies}

A two year epidemiological study is planned to determine the part played by salicylates, insecticides, and other risk factors previously implicated in the aetiology of Reye's syndrome in the British Isles, ${ }^{310}$ using the surveillance scheme to ascertain cases. The case definition will be slightly modified (appendix) to make it more comparable to that used by the Centers for Disease Control, while maintaining sensitivity. Clinicians will be informed, via the British Paediatric Association and the medical press, of the starting date of the study, and it would be most helpful if cases could be reported and appropriate specimens obtained as early as possible.

A follow up study of survivors reported to the surveillance scheme is also planned, in order to determine whether other metabolic disorders have subsequently been diagnosed and thus to evaluate further the specificity of the case definition.

\section{Parents' group}

A parents' group has been founded, with the objectives of providing mutual support and information to parents of children with Reye's syndrome and of promoting interest and research into the syndrome. It is the National Reye's Syndrome Foundation of the United Kingdom, 4a Crown Street, Harrow-on-theHill, Middlesex.

The surveillance scheme could not be run without the interest and support of paediatricians, pathologists, and microbiologists. We thank all those who have reported cases to the scheme and provided follow up information and pathological specimens. We also thank Dr Pereira of the Virus Reference Laboratory, Central Public Health Laboratory, for kindly agreeing to store the specimens.

\section{Appendix}

Modified case definition: acute, non-inflammatory encephalopathy of uncertain cause with microvesicular fatty infiltration of the liver: ( $a$ ) confirmed by: biopsy (histology or ultrastructure, or both) or necropsy (macroscopically large pale and fatty liver or histological/ultrastructural confirmation); or (b) suggested by a serum aspartate transaminase or alanine transaminase activity or blood ammonia concentration greater than three times the upper limit of normal for the laboratory.

\section{References}

${ }^{1}$ Reye RDK, Morgan G, Baral J. Encephalopathy and fatty degeneration of the viscera: a disease entity in childhood. Lancet 1963;ii:749-52.

${ }^{2}$ Partin JC, Bore K, Partin JS, Schubert WK. Liver and muscle ultrastructure in Reye's syndrome. In: Crocker JFS, ed. Reye's syndrome II. New York: Grune and Stratton, 1979:217-37.

${ }^{3}$ Sullivan-Bolyai JZ, Corey L. Epidemiology of Reye syndrome. Epidemiologic Reviews $1981 ; 3: 1-26$.

4 Bellman MH, Ross EM, Miller DL. Reye's syndrome in children under three years old. Arch Dis Child 1982;57:259-63.

${ }^{5}$ Levin M, Hjelm M, Kay JDS, et al. Haemorrhagic shock and encephalopathy: a new syndrome with a high mortality in young children. Lancet $1983 ;$ ii :64-7.

${ }^{6}$ Dhiensiri K, Sinavatana P, Lertsookprasert S. Reye's syndrome in north eastern Thailand. In: Crocker JFS, ed. Reye's syndrome II. New York: Grune and Stratton, 1979:77-99.

7 Yamashita F, Yamamoto M, Okada S, Yoshida I, Yoshino M. Reye's syndrome in Japan: epidemiology, clinical features and indicators for mortality and the sequelae. In: Crocker JFS, ed. Reye's syndrome II. New York: Grune and Stratton, 1979:51-69.

${ }^{\rtimes}$ Corey L, Rubin RJ, Bregman D, Gregg MB. Diagnostic criteria for influenza B-associated Reye's syndrome: clinical vs pathologic criteria. Pediatrics 1977;60:702-8.

${ }^{9}$ Mowat DP. Reye's syndrome: 20 years on. Br Med F 1983;286:1999-2001.

10 Bellman MH, Hall SM. Aetiology of Reye's syndrome. Arch Dis Child 1983;58:670-2.

\section{Clinical curio: an unusual case of a lost tampon}

A 17 year old white sixth form student was referred to the hospital from the local family planning clinic for the removal of a tampon retained in the vagina. This was the first occasion on which a tampon had been used by the patient, whose menstrual history over the preceding four years had been regular, bleeding lasting three to four days every 28 days. Insertion of the tampon was uncomfortable and was followed by intermittent severe suprapubic and pelvic pain. She attempted to remove the tampon but succeeded only in breaking the attached string; she then attended her family doctor. Eighteen months earlier her family doctor had diagnosed a narrow vagina and advised her to dilate it digitally. On this visit the doctor was unable to remove the tampon and sent her to the family planning clinic, where further attempts to remove it were also unsuccessful.

On arrival at the gynaecology clinic the patient was frightened and in pain. She was able to give a coherent history and commented that each time she passed urine the pain was aggravated. No attempt was made to examine her vaginally in the clinic and she was admitted for examination under general anaesthesia, nine hours after insertion of the tampon. External secondary sex characteristics were normal. The urethral meatus was patulous and bleeding. No vaginal introitus was apparent, but closer inspection revealed a pinpoint hymenal orifice, through which altered blood could be expressed. Digital examination of the urethra confirmed that the tampon was within the bladder. A narrow vaginal Sims speculum was passed along the urethra, the tampon was grasped with a double toothed volsellum and gently extracted through the urethra. The tampon had expanded to measure $2 \mathrm{~cm}$ in diameter. Subsequent cystoscopy showed haemorrhagic mucosa, and a bladder wash was performed. The hymen was dilated to disclose a normal vagina and cervix.

The next day the girl passed urine freely and without stress incontinence, and she was discharged home to complete a course of prophylactic antibiotics.

Many different foreign bodies have been retrieved from the bladder but only one similar case has been described in which a virginal college student, used to using vaginal tampons successfully, developed retention of urine after misplacement of a tampon. ${ }^{1}$

I thank Mr A Johnson for his helpful comments.-SIMON EMERY, registrar in obstetrics and gynaecology, Sheffield.

' Milstein R. Urinary tamponade due to a tampon. $\mathcal{F} A M A$ 1977;238:126. 